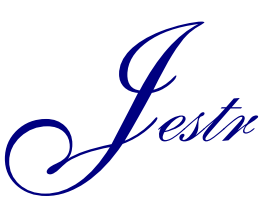

\title{
Simulating the Impact of Activity Uncertainties and Risk Combinations in R\&D Projects
}

\author{
Ali Chenarani, E. A. Druzhinin and D. N. Kritskiy \\ National Aerospace University «KhAI», Kharkiv, Ukraine
}

Received 10 April 2017; Accepted 14 August 2017

\begin{abstract}
The quantifiable consequences of uncertainty are simulated and analyzed for R\&D projects. These consequences include variation in duration and cost of activities and the presence of risk factors in project. Categorizing risks into four types is proposed according to their impact on the main constraints of the project. The most prominent type of risk in R\&D projects is the rework risk but common software packages for project management are not able to simulate them. A discrete event based Monte Carlo simulation method is employed for project simulation. The required project and risk data for simulation are represented by means of dependency structure matrix (DSM). For calculating the effects of rework risk, BFS graph traversal algorithm is used. A simulation program is developed and implemented in a small turbojet engine preliminary design project. The results of this research can improve the effectiveness of decision-making process by project manager where choosing appropriate method for reducing risk effects under uncertainty conditions is required.
\end{abstract}

Keywords: uncertainty, project risk, discrete event simulation, Monte Carlo method, BFS graph traversal

\section{Introduction}

Risks are present in every project. They can affect the quality of achieving the goals and the project success and in extreme cases, they can lead to its failure. There are prevalent researches and discussions for conceptualizing risk and its sources not only in in the project management literature but also in other scientific fields such as economics, reliability engineering, ecology, psychology, health, environment etc.[1-8]. Most researchers agree that risk results from uncertainty and they are not theoretically synonymous. However, some of them believe that they are the same concepts.

Project Management Body of Knowledge [9] defines risk as "an uncertain event or condition that, if occurs, has a positive or a negative effect on at least one project objective, such as time, cost, scope, or quality". Although various methods and standards have been introduced for risk management, they suggest the common steps and only differ in some details. The main steps include risk identification, evaluation, response selection, control and monitoring.

The levels and characteristics of risks in a project mainly depend on the project context and its type. In our research case, which is research and development (R\&D) project, the project is associated with high uncertainty and risk level. This is due to factors such as considerable degree of innovation and novelty; unclear and insufficient information about the product; complex interrelationships and often using large variety of approaches and specialties. In

\footnotetext{
*E-mail address: alichen.va@gmail.com

ISSN: $1791-2377$ @ 2017 Eastern Macedonia and Thrace Institute of Technology. All rights reserved.

doi:10.25103/jestr.104.01
}

addition, risk management in the early stages of the project where the main decisions about the project are made has a vital importance [10].

One of the main characteristics of $\mathrm{R} \& \mathrm{D}$ projects, especially in their early phases is the rework risk. This type of risk occurs when the result of terminating an activity leads to the necessity of repeating some finished activities. The main sources of this type of risk are inherent coupling between activities, poor activity sequencing, incomplete activities, poor communication, input changes and mistakes [11]. There is not the possibility of rework modeling in common project management softwares such as Microsoft project and Primavera. Some research on modeling and evaluating different aspects of rework risk is done [12-16]. However, they do not consider the effect of different combinations of risk types (including rework risk) while the duration and cost of the activities are not deterministic and can be represented by probability distributions.

Accordingly, in present work we will try to simulate the project with different risk types that affect project time, cost and scope in presence of uncertainty about the duration and cost of activities. For this purpose, Monte Carlo Simulation (MCS) and Design Structure Matrix (DSM) are used. Next sections of the paper are organized as follows: second section covers a literature review. The third section describes the simulation basics and algorithm. In fourth section, results of simulation for the preliminary design of a small turbojet engine, which can be used in ultralight airplanes or unmanned aerial vehicles are represented and finally, in last section we will analyze the results and provide some conclusions. 


\section{Literature review}

\subsection{Risk and uncertainty: definitions and relationship}

There is not a unique understanding and definition of risk and uncertainty and their relationship in project. According to [17] uncertainty in projects may be interpreted as two concepts: variability (a measurable factor can take on a range of possible values) and ambiguity (uncertainty of meaning or uncertainty about the event itself with a lack of clarity over some aspect of its existence). Atkinson et al. [3] mention three key areas of uncertainty as uncertainty associated with estimating, uncertainty associated with project parties, and uncertainty associated with stages of the project life cycle. They believe that uncertainty is particularly predominant at the early stages of a project. Perminova et al. [5] define uncertainty as "a context for risks as events having a negative impact on the project's outcomes, or opportunities, as events that have beneficial impact on project performance". From Hillson's point of view [4] "Risk is measurable uncertainty; uncertainty is unmeasurable risk". Mazur et al. [18] describe project risk through the interrelated categories: uncertainty, risk and loss. Uncertainty is characterized by incomplete and/or unreliable source of information about the project and probabilistic character of future events and can be described and analyzed by mathematical concepts and tools. Then, project risk occurs as the result of uncertainty about the future events, which in turn causes to loss (damage). De Meyer et al. [19] proposed four categories of uncertainty in project as they relate to project management techniques, which are variation, foreseen uncertainty, unforeseen uncertainty and chaos and suggested recommendations for each category.

In present work, our assumption about the uncertainty types is in accordance with last work. In other words, the first uncertainty type (variation) is expressed with probability distributions of parameters (activity durations and costs in this study). Risks are the result of second uncertainty type (foreseen uncertainty) and in accordance with project management literature they can be represented by two parameters, probability of occurrence $(\mathrm{P})$ and impact (I). The third and fourth type of uncertainty are not quantifiable and can be evaluated by qualitative methods. In our study, we will simulate the effect of first two categories on project performance.

\subsection{Methods for assessment and management of risk and uncertainty}

There is a considerable amount of research in the field of risk and uncertainty assessment and management. The most known techniques are the probability-impact matrix, Pareto diagrams, stochastic simulation (such as Monte Carlo), decision tree, Failure Mode and Effect Analysis (FMEA), Bayesian Network (BN) and sensitivity analysis.

Druzhinin [20] considers the risk concept from project stability point of view and proposes a risk oriented method for stabilizing project context. Some researchers used the Bayesian Network (BN) modelling framework for assessing project risk and uncertainty [21-24]. Nguyen et al. [25] developed ProRisk methodology which serves as a decisionmaking tool to choose the best risk treatment strategy. In [26], authors used a probabilistic fuzzy method and fuzzy IF-THEN rules for innovative project risk assessment while Rodríguez et al. [27] employed a combination of Fuzzy Analytic Hierarchy Process (FAHP) and Fuzzy Inference System (FIS) for assessing risks of information technology projects. Muriana \& Vizzini [28] proposed a deterministic technique for assessing and preventing project risks, with regard to cost, schedule, and quality at determined time steps, which are called WPS. the effect of seasonal type uncertainty (weather conditions) on some activities by means of Monte Carlo simulation is analyzed by Acebes et al. [29].

Several researchers have employed simulation models to analyze iteration and rework in projects. Browning \& Eppinger [12] modeled reworks and the information flows between tasks with a discrete event simulation-based method. This work was further developed by Cho \& Eppinger [13]. They proposed the second-generation DSM simulation-based analysis for complex design process. Li \& Moon [30] used Arena simulation software to assess the overlapping and iteration in product development (PD) projects. In [14] authors proposed that the iteration and overlapping are the main causes of uncertainty and ambiguity in the PD process. They used Arena software to reveal how uncertainty of iteration affects project schedule.

As mentioned in last section, our review shows that the combined effect of different risk types (including rework risk) and the uncertainty of duration and cost of the activities have not considered completely so far which will be the subject of this work.

\section{Simulation basics and the solution algorithm}

\subsection{Risk types}

The famous traditional project management triangle as is shown in Fig. 1 consists of three constraints i.e. time, cost and scope. In some sources, the quality is the fourth element and considered as a function of other three constraints.

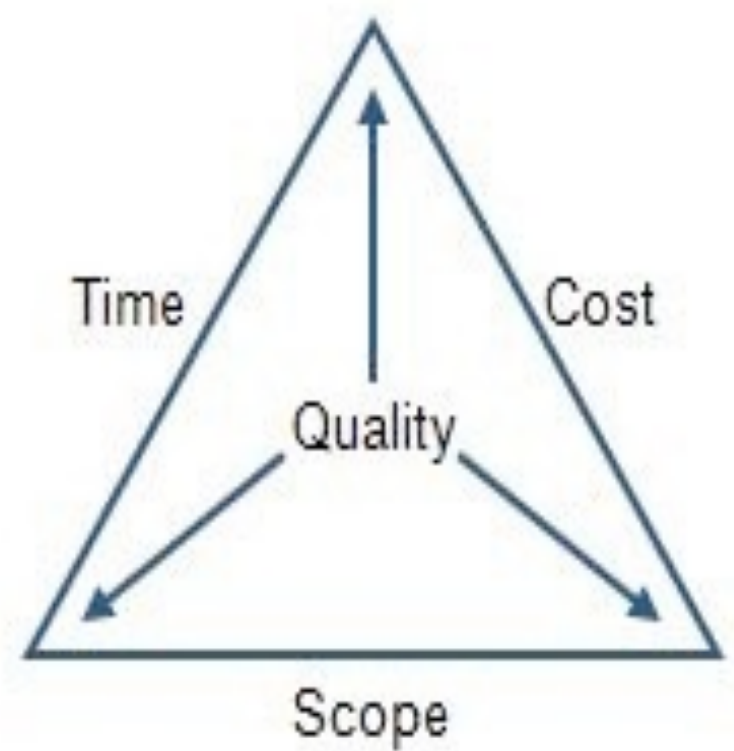

Fig. 1. Project constraints triangle

We assume that in case of happening risks, these three elements on activities change in order to maintain the project quality within the predefined level. Also, we propose classifying risks into four categories according to their effects on project constraints triangle i.e. time, cost and scope (amount of required work) as shown in Tab. 1: 
Table 1. Proposed risk types and their characteristics

\begin{tabular}{|c|c|c|c|c|}
\hline $\begin{array}{l}\text { Risk } \\
\text { type }\end{array}$ & \begin{tabular}{|l} 
Risk \\
name
\end{tabular} & Description & Examples & \begin{tabular}{|l|}
$\begin{array}{l}\text { Corresponding } \\
\text { constraint }\end{array}$ \\
\end{tabular} \\
\hline 1 & $\begin{array}{l}\text { Delay } \\
\text { risk }\end{array}$ & $\begin{array}{l}\text { Affects } \\
\text { activity } \\
\text { durations }\end{array}$ & $\begin{array}{l}\text { Delay in } \\
\text { receiving } \\
\text { required } \\
\text { information, } \\
\text { bad weather } \\
\text { conditions, } \\
\text { late decision } \\
\text { made by } \\
\text { managers } \\
\text { Inflation, }\end{array}$ & time \\
\hline 2 & $\begin{array}{l}\text { Cost } \\
\text { risk }\end{array}$ & $\begin{array}{l}\text { Affects } \\
\text { activity } \\
\text { costs }\end{array}$ & $\begin{array}{l}\text { increased } \\
\text { prices or } \\
\text { tariffs, paying } \\
\text { a fine }\end{array}$ & cost \\
\hline 3 & $\begin{array}{l}\text { Excess } \\
\text { work } \\
\text { risk }\end{array}$ & $\begin{array}{l}\text { Causes the } \\
\text { additional } \\
\text { work for the } \\
\text { same } \\
\text { activity }\end{array}$ & $\begin{array}{l}\text { Unplanned } \\
\text { experiments } \\
\text { for verifying } \\
\text { designed } \\
\text { parts, } \\
\text { proposing new } \\
\text { technologies } \\
\text { or solutions by } \\
\text { project team }\end{array}$ & scope \\
\hline 4 & $\begin{array}{l}\text { Rework } \\
\text { risk }\end{array}$ & $\begin{array}{l}\text { Causes } \\
\text { repeating } \\
\text { some or all } \\
\text { parts of a } \\
\text { group of } \\
\text { activities } \\
\text { that are } \\
\text { influenced } \\
\text { by rework }\end{array}$ & $\begin{array}{l}\text { Data loss, } \\
\text { insufficient } \\
\text { accuracy of } \\
\text { simulations, } \\
\text { test failure, } \\
\text { changes in } \\
\text { standards and } \\
\text { regulations }\end{array}$ & scope \\
\hline
\end{tabular}

It can be stated that first, second and third risk types affect the same activity, while the rework risk affects a set of activities, which are located on rework path. Also, in our study we assume that the happening or not happening the first, second and third type of risk is determined at the beginning of the activity, while for the fourth risk type (rework risk) after finishing the activity and analyzing its results, the need for adding rework to other activities is checked. Each risk is characterized by two important parameters: probability of occurrence $(\mathrm{P})$ and its impact (I). For determining these parameters, a variety of methods can be used including expert method, past projects experience, using empirical data.

\subsection{Required data for simulation}

We propose the matrix representation for assigning the activity dependencies and risk characteristics. These matrices will be used for assigning initial data, which are required for risk simulation. For this purpose, three square matrices are suggested which are activity dependencies matrix, also known as dependency structure matrix (DSM), risk probability matrix (RPM) and risk impact matrix (RIM). Each row (or column) of these matrices represents one of the project activities. In other words, the size of all matrices equals to the number of project activities.

DSM suggested first time by Steward [31] and provides a simple way to visualize and analyze the dependencies of complex systems. The lower triangular part of DSM (subdiagonal elements) has binary values. In modelling process activities with DSM, the value of element $j i$ (row $j$, column $i$ ) is unity when activity $i$ is the predecessor of activity $j$. Otherwise, the value of this element is zero (or left empty). Nonzero elements on the upper part of DSM show possible reworks (iterations) in project. In this work, we propose to use integer values instead of Boolean values on superdiagonal elements for representing the maximum number of possible reworks. Specially, in early phases of R\&D projects where performing a rework more than one time is likely, this suggestion seems more appropriate. Therefore, we have:

$$
\operatorname{DSM}(i, j)= \begin{cases}0 & \text { if } i>j \text { and } j \text { is not predecessor of } i \\ 1 & \text { if } i>j \text { and jis predecessor of i } \\ 0 & \text { if } i=j \\ 0 & \text { if } i<j \text { without possible } / \text { w from } j \text { to } i \\ n & \text { if } i<j \text { with max.n possible r/ws from } j \text { to } i\end{cases}
$$

The next matrix is Risk Probability Matrix (RPM) in which the probabilities of occurring different types of risks are shown. We use diagonal elements of this matrix for representing the first three types of risk, which act upon the same activity. For distinguishing these three risk types in this matrix, we use the letter " $t$ " for delay risk, "c" for cost risk and "w" for excess work risk. Superdiagonal elements of this matrix that are filled in accordance to their corresponding elements in DSM matrix indicate the probability of occurring rework risks.

The third matrix is risk impact matrix (RIM) which represents the impact of risks in case of their occurrence. Similar to RPM, we use diagonal elements of RIM for indicating the impact of first three risk types. The values of these elements are expressed in terms of time unit (day, week, month and so on) for delay risks, cost (dollars or other currencies) for cost risks and additional work (a fraction of corresponding activity's work amount) for excess work risks. In case of rework risks, the filled elements of upper triangular part of RIM (corresponding to filled elements of DSM) show the impact of occurring reworks in terms of average fraction of original work or effort that must be repeated. Furthermore, after accomplishing the rework of an activity, the updated outputs and results of that activity cause some rework on its successor activities. This type of rework is also known as second order rework [12] and can be estimated by the ratio of data, documentation, raw material received and used by successor activity. In order to taking account this aspect of rework risk impact, subdiagonal part of RIM is used. Therefore, the fraction of each activity's work that is repeated as the result of rework on its preceding activity is represented by lower triangular part of RIM.

Also, there is another parameter that affects the volume of rework. This parameter is called improvement curve and takes into account learning and adaptation abilities of project team $[12,32]$. For the simplicity, we represent it as a constant coefficient for each activity. It means that for first time, each activity takes $100 \%$ of cost and duration to perform, but accomplishing the same work for the second and subsequent times, is calculated by multiplying the original value to the improvement curve coefficient.

For representing uncertainty about duration and cost of activities, we employ probability distributions. This type of uncertainty as mentioned in first section is called variation. In project management, from diverse variety of probability 
distributions, the most widely used distributions are triangular, beta and normal distributions. While the beta and triangular distributions usually are used for individual activities, the normal distribution is the consequence of the interaction of activity distributions in project [33]. In this study, we chose triangular distribution. Any triangular distribution is determined by three parameters: optimistic estimate (opt.); most likely estimate (ml.) and pessimistic estimate (pes.).

The initial data of our study, which is small turbojet engine preliminary design project, are shown in Fig. 2 and tables 2-5 as follows: project network diagram (Fig. 2), WBS, DSM, duration and cost distributions data and improvement curve values for each activity (Tab. 2), specifications of project risks (Tab. 3), risk probability matrix (RPM) in Tab. 4 and risk impact matrix (RIM) in
Tab. 5. The required data are obtained with the help of experts.

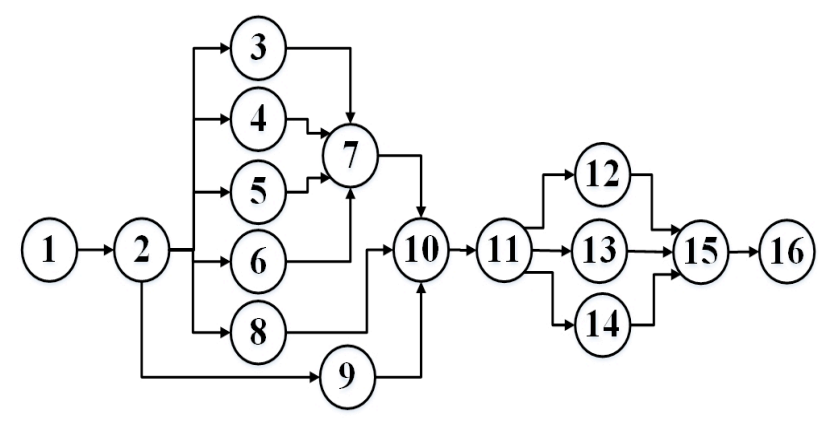

Fig. 2. Project network diagram

Table 2. WBS, DSM, duration and cost data and improvement curve values

\begin{tabular}{|c|c|c|c|c|c|c|c|c|c|c|c|c|c|c|c|c|c|c|c|c|c|c|c|c|}
\hline \multirow{2}{*}{ No } & \multirow{2}{*}{ Activity name } & \multicolumn{16}{|c|}{ DSM } & \multicolumn{3}{|c|}{ Duration (week) } & \multicolumn{3}{|c|}{$\begin{array}{l}\text { Cost } \\
\text { (K \$) }\end{array}$} & \multirow{2}{*}{$\begin{array}{l}\text { IC } \\
\%\end{array}$} \\
\hline & & 1 & 2 & 3 & 4 & 5 & 6 & 7 & 8 & 9 & 10 & 11 & 12 & 13 & 14 & 15 & 16 & opt & $\mathrm{ml}$ & pes & opt & $\mathbf{m l}$ & pes & \\
\hline 1 & Analyze design point and off design studies, cycle selection & 0 & 0 & 0 & 0 & 0 & 0 & 0 & 0 & 0 & 1 & 0 & 0 & 0 & 0 & 0 & 1 & 2.5 & 3 & 4.5 & 16 & 20 & 30 & 0.7 \\
\hline 2 & Perform sizing and assign parameters for subsystems & 1 & 0 & 0 & 0 & 0 & 0 & 2 & 0 & 0 & 1 & 0 & 0 & 0 & 0 & 0 & 0 & 1.5 & 2 & 3 & 5 & 7 & 10 & 0.5 \\
\hline 3 & Perform compressor calculations & 0 & 1 & 0 & 0 & 0 & 0 & 0 & 0 & 0 & 0 & 0 & 0 & 0 & 0 & 0 & 0 & 3 & 4 & 6 & 16 & 20 & 30 & 0.8 \\
\hline 4 & Perform turbine calculations & 0 & 1 & 0 & 0 & 0 & 0 & 0 & 0 & 0 & 0 & 0 & 0 & 0 & 0 & 0 & 0 & 3 & 4 & 6 & 16 & 20 & 30 & 0 \\
\hline 5 & Perform combustion chamber calculations & 0 & 1 & 0 & 0 & 0 & 0 & 0 & 0 & 0 & 0 & 0 & 0 & 0 & 0 & 0 & 0 & 3 & 4 & 6 & 16 & 20 & 30 & 0.8 \\
\hline 6 & Perform nuzzle calculations & 0 & 1 & 0 & 0 & 0 & 0 & 0 & 0 & 0 & 0 & 0 & 0 & 0 & 0 & 0 & 0 & 3 & 4 & 6 & 10 & 13 & 18 & 0.8 \\
\hline 7 & Improve accuracy and optimize main components design & 0 & 0 & 1 & 1 & 1 & 1 & 0 & 0 & 0 & 0 & 0 & 0 & 0 & 0 & 0 & 0 & 1.5 & 2 & 4 & 8 & 10 & 16 & 0.6 \\
\hline 8 & Perform control system and accessories calculations & 0 & 1 & 0 & 0 & 0 & 0 & 0 & 0 & 0 & 0 & 0 & 0 & 0 & 0 & 0 & 0 & 5 & 6 & 8 & 12 & 15 & 20 & 0.8 \\
\hline 9 & Evaluate other engine parameters (reliability, noise, pollution,...) & 0 & 1 & 0 & 0 & 0 & 0 & 0 & 0 & 0 & 0 & 0 & 0 & 0 & 0 & 0 & 0 & 5 & 6 & 8 & 20 & 25 & 35 & 0.7 \\
\hline 10 & Refine parameters and finalize design & 0 & 0 & 0 & 0 & 0 & 0 & 1 & 1 & 1 & 0 & 0 & 0 & 0 & 0 & 0 & 0 & 1.5 & 2 & 4 & 13 & 15 & 25 & 0.6 \\
\hline 11 & Develop force diagram and components configurations & 0 & 0 & 0 & 0 & 0 & 0 & 0 & 0 & 0 & 1 & 0 & 0 & 0 & 0 & 2 & 1 & 1.5 & 2 & 3 & 10 & 15 & 22 & 0.9 \\
\hline 12 & Prepare and test the engine maket & 0 & 0 & 0 & 0 & 0 & 0 & 0 & 0 & 0 & 0 & 1 & 0 & 0 & 0 & 0 & 0 & 2 & 3 & 5 & 20 & 25 & 40 & 0.6 \\
\hline 13 & Structural and thermodynamical calculations of configurations & 0 & 0 & 0 & 0 & 0 & 0 & 0 & 0 & 0 & 0 & 1 & 0 & 0 & 0 & 0 & 0 & 3 & 4 & 6 & 35 & 40 & 60 & 0.7 \\
\hline 14 & Evaluate qualitative parameters (remontability, standardization, ... ) & 0 & 0 & 0 & 0 & 0 & 0 & 0 & 0 & 0 & 0 & 1 & 0 & 0 & 0 & 0 & 0 & 3 & 4 & 7 & 20 & 25 & 35 & 0.8 \\
\hline 15 & Finalize the configuration of engine and components & 0 & 0 & 0 & 0 & 0 & 0 & 0 & 0 & 0 & 0 & 0 & 1 & 1 & 1 & 0 & 0 & 1.5 & 2 & 4 & 8 & 10 & 15 & 0.6 \\
\hline 16 & Prepare documents and terminate the project & 0 & 0 & 0 & 0 & 0 & 0 & 0 & 0 & 0 & 0 & 0 & 0 & 0 & 0 & 1 & 0 & 2.5 & 3 & 3.5 & 18 & 20 & 26 & 0.8 \\
\hline
\end{tabular}

Table 3. Specifications of project risks

\begin{tabular}{|c|c|c|c|c|c|}
\hline & Risk description & Risk type & $\mathbf{P}$ & $\mathbf{I}$ & max. no. \\
\hline 1 & $\begin{array}{l}\text { Calculations of gas generator components cannot satisfy engine } \\
\text { requirements. Some engine parameters need revision. }\end{array}$ & Rework from 7 to 2 & 0.6 & 0.4 & 2 \\
\hline 2 & $\begin{array}{l}\text { Some engine parameters need modifications as the result of accessories } \\
\text { and other engine parameters calculations }\end{array}$ & Rework from 10 to 2 & 0.5 & 0.4 & 1 \\
\hline 3 & $\begin{array}{l}\text { Selected engine cycle (design point) should be changed as a result of } \\
\text { calculations of its components and aggregates }\end{array}$ & Rework from 10 to 1 & 0.3 & 0.2 & 1 \\
\hline 4 & $\begin{array}{l}\text { When finalizing engine configuration, specified configuration of some } \\
\text { engine components should be revised }\end{array}$ & Rework from 15 to 11 & 0.4 & 0.4 & 2 \\
\hline 5 & Force diagram and component configurations need changing & Rework from 16 to 11 & 0.2 & 0.3 & 1 \\
\hline 6 & $\begin{array}{l}\text { Selected engine cycle should be changed when making decision about } \\
\text { closing the project }\end{array}$ & Rework from 16 to 1 & 0.2 & 0.1 & 1 \\
\hline 7 & $\begin{array}{l}\text { Hardware or software cannot afford complicated computations (more } \\
\text { powerful software or parallel processing needed) }\end{array}$ & Cost risk on 7 & 0.3 & 15 & - \\
\hline 8 & Delay in receiving necessary data for starting the activity & Delay risk on 10 & 0.5 & 1 & - \\
\hline 9 & $\begin{array}{l}\text { Preparing and testing the engine maket needs performing unforeseen } \\
\text { volume of work }\end{array}$ & Excess work on 12 & 0.3 & 0.4 & - \\
\hline 10 & $\begin{array}{l}\text { Making decision about terminating the project delayed by manager, } \\
\text { costumer or administration }\end{array}$ & Delay risk on 16 & 0.7 & 1 & - \\
\hline
\end{tabular}


Table 4. Risk probability matrix (RPM)

\begin{tabular}{|c|c|c|c|c|c|c|c|c|c|c|c|c|c|c|c|c|}
\hline & $\mathbf{1}$ & $\mathbf{2}$ & $\mathbf{3}$ & $\mathbf{4}$ & $\mathbf{5}$ & $\mathbf{6}$ & $\mathbf{7}$ & $\mathbf{8}$ & $\mathbf{9}$ & $\mathbf{1 0}$ & $\mathbf{1 1}$ & $\mathbf{1 2}$ & $\mathbf{1 3}$ & $\mathbf{1 4}$ & $\mathbf{1 5}$ & $\mathbf{1 6}$ \\
\hline $\mathbf{1}$ & 0 & 0 & 0 & 0 & 0 & 0 & 0 & 0 & 0 & 0.3 & 0 & 0 & 0 & 0 & 0 & 0.2 \\
\hline $\mathbf{2}$ & 1 & 0 & 0 & 0 & 0 & 0 & 0.6 & 0 & 0 & 0.5 & 0 & 0 & 0 & 0 & 0 & 0 \\
\hline $\mathbf{3}$ & 0 & 1 & 0 & 0 & 0 & 0 & 0 & 0 & 0 & 0 & 0 & 0 & 0 & 0 & 0 & 0 \\
\hline $\mathbf{4}$ & 0 & 1 & 0 & 0 & 0 & 0 & 0 & 0 & 0 & 0 & 0 & 0 & 0 & 0 & 0 & 0 \\
\hline $\mathbf{5}$ & 0 & 1 & 0 & 0 & 0 & 0 & 0 & 0 & 0 & 0 & 0 & 0 & 0 & 0 & 0 & 0 \\
\hline $\mathbf{6}$ & 0 & 1 & 0 & 0 & 0 & 0 & 0 & 0 & 0 & 0 & 0 & 0 & 0 & 0 & 0 & 0 \\
\hline $\mathbf{7}$ & 0 & 0 & 1 & 1 & 1 & 1 & $\mathrm{P}=.3$ & 0 & 0 & 0 & 0 & 0 & 0 & 0 & 0 & 0 \\
\hline $\mathbf{8}$ & 0 & 1 & 0 & 0 & 0 & 0 & 0 & 0 & 0 & 0 & 0 & 0 & 0 & 0 & 0 & 0 \\
\hline $\mathbf{9}$ & 0 & 1 & 0 & 0 & 0 & 0 & 0 & 0 & 0 & 0 & 0 & 0 & 0 & 0 & 0 & 0 \\
\hline $\mathbf{1 0}$ & 0 & 0 & 0 & 0 & 0 & 0 & 1 & 1 & 1 & $\mathrm{Pt}=.5$ & 0 & 0 & 0 & 0 & 0 & 0 \\
\hline $\mathbf{1 1}$ & 0 & 0 & 0 & 0 & 0 & 0 & 0 & 0 & 0 & 1 & 0 & 0 & 0 & 0 & 0.4 & 0.2 \\
\hline $\mathbf{1 2}$ & 0 & 0 & 0 & 0 & 0 & 0 & 0 & 0 & 0 & 0 & 1 & $\mathrm{PW}=3$ & 0 & 0 & 0 & 0 \\
\hline $\mathbf{1 3}$ & 0 & 0 & 0 & 0 & 0 & 0 & 0 & 0 & 0 & 0 & 1 & 0 & 0 & 0 & 0 & 0 \\
\hline $\mathbf{1 4}$ & 0 & 0 & 0 & 0 & 0 & 0 & 0 & 0 & 0 & 0 & 1 & 0 & 0 & 0 & 0 & 0 \\
\hline $\mathbf{1 5}$ & 0 & 0 & 0 & 0 & 0 & 0 & 0 & 0 & 0 & 0 & 0 & 1 & 1 & 1 & 0 & 0 \\
\hline $\mathbf{1 6}$ & 0 & 0 & 0 & 0 & 0 & 0 & 0 & 0 & 0 & 0 & 0 & 0 & 0 & 0 & 1 & $\mathrm{P}=.7$ \\
\hline
\end{tabular}

Table 5. Risk impact matrix (RIM)

\begin{tabular}{|c|c|c|c|c|c|c|c|c|c|c|c|c|c|c|c|c|}
\hline & $\mathbf{1}$ & $\mathbf{2}$ & $\mathbf{3}$ & $\mathbf{4}$ & $\mathbf{5}$ & $\mathbf{6}$ & $\mathbf{7}$ & $\mathbf{8}$ & $\mathbf{9}$ & $\mathbf{1 0}$ & $\mathbf{1 1}$ & $\mathbf{1 2}$ & $\mathbf{1 3}$ & $\mathbf{1 4}$ & $\mathbf{1 5}$ & $\mathbf{1 6}$ \\
\hline $\mathbf{1}$ & 0 & 0 & 0 & 0 & 0 & 0 & 0 & 0 & 0 & 0.3 & 0 & 0 & 0 & 0 & 0 & 0.2 \\
\hline $\mathbf{2}$ & 1 & 0 & 0 & 0 & 0 & 0 & 0.6 & 0 & 0 & 0.5 & 0 & 0 & 0 & 0 & 0 & 0 \\
\hline $\mathbf{3}$ & 0 & 1 & 0 & 0 & 0 & 0 & 0 & 0 & 0 & 0 & 0 & 0 & 0 & 0 & 0 & 0 \\
\hline $\mathbf{4}$ & 0 & 1 & 0 & 0 & 0 & 0 & 0 & 0 & 0 & 0 & 0 & 0 & 0 & 0 & 0 & 0 \\
\hline $\mathbf{5}$ & 0 & 1 & 0 & 0 & 0 & 0 & 0 & 0 & 0 & 0 & 0 & 0 & 0 & 0 & 0 & 0 \\
\hline $\mathbf{6}$ & 0 & 1 & 0 & 0 & 0 & 0 & 0 & 0 & 0 & 0 & 0 & 0 & 0 & 0 & 0 & 0 \\
\hline $\mathbf{7}$ & 0 & 0 & 1 & 1 & 1 & 1 & $\mathrm{P}=.3$ & 0 & 0 & 0 & 0 & 0 & 0 & 0 & 0 & 0 \\
\hline $\mathbf{8}$ & 0 & 1 & 0 & 0 & 0 & 0 & 0 & 0 & 0 & 0 & 0 & 0 & 0 & 0 & 0 & 0 \\
\hline $\mathbf{9}$ & 0 & 1 & 0 & 0 & 0 & 0 & 0 & 0 & 0 & 0 & 0 & 0 & 0 & 0 & 0 & 0 \\
\hline $\mathbf{1 0}$ & 0 & 0 & 0 & 0 & 0 & 0 & 1 & 1 & 1 & $\mathrm{Pt}=.5$ & 0 & 0 & 0 & 0 & 0 & 0 \\
\hline $\mathbf{1 1}$ & 0 & 0 & 0 & 0 & 0 & 0 & 0 & 0 & 0 & 1 & 0 & 0 & 0 & 0 & 0.4 & 0.2 \\
\hline $\mathbf{1 2}$ & 0 & 0 & 0 & 0 & 0 & 0 & 0 & 0 & 0 & 0 & 1 & $\mathrm{P}=3$ & 0 & 0 & 0 & 0 \\
\hline $\mathbf{1 3}$ & 0 & 0 & 0 & 0 & 0 & 0 & 0 & 0 & 0 & 0 & 1 & 0 & 0 & 0 & 0 & 0 \\
\hline $\mathbf{1 4}$ & 0 & 0 & 0 & 0 & 0 & 0 & 0 & 0 & 0 & 0 & 1 & 0 & 0 & 0 & 0 & 0 \\
\hline $\mathbf{1 5}$ & 0 & 0 & 0 & 0 & 0 & 0 & 0 & 0 & 0 & 0 & 0 & 1 & 1 & 1 & 0 & 0 \\
\hline $\mathbf{1 6}$ & 0 & 0 & 0 & 0 & 0 & 0 & 0 & 0 & 0 & 0 & 0 & 0 & 0 & 0 & 1 & $\mathrm{P}=.7$ \\
\hline
\end{tabular}

\subsection{Simulation algorithm for one run}

In present study, we use a discrete event simulation to obtain cost and time distributions of project with risk and uncertainty effects. The main idea is using unfinished work vector (W), a vector of length $n$ (number of project activities) that contains the amount of work to be done for each activity and initially set to all " 1 "s $\left(\mathrm{W}_{\mathrm{i}}=1\right)$ to indicate $100 \%$ of the work remains for all activities [12].

During simulation process, values of unfinished work vector change. By advancing the simulation process forward (project progress) the amount of unfinished work for active activities decreases depending on the elapsed time, while occurring third or fourth risk types (excess work and rework) cause increase in corresponding activity's unfinished work value. At each step of simulation which is called event, all unfinished activities with finished predecessors are found and the possibility of occurring first, second or third risk type for them are checked by generating a random number in $[0,1]$ interval and comparing with the corresponding probability value in the RPM (probability matrix). If risk happens, the impact value, which can be time, cost or excess work is obtained from RIM (impact matrix) and is added to the respective values of that activity.

After checking and adding the effects of these three types of risk, the time for occurring next event is computed by finding the minimum remained duration of all activated activities. At the end of obtained next event time, the cumulative duration is calculated and cumulative cost and unfinished work vector (W) for active activities are updated. In this study, we assume that there is a linear relationship between each activity's work amount and its duration and cost. If there is another relationship between them, it can be applied in this step.

At the end of each event, for finished activities, the occurrence of rework risk is checked by the same way as mentioned for other risk types. Again, if risk occurs, the calculated reworks and second order reworks of affected activities are added to unfinished work vector for the next event.

Theory of graph is used for identification of activities that are affected by rework risks. For this end, at the beginning of the simulation, the directed graph of project is created using the binary data of lower triangular part of dependency structure matrix (DSM). Then, BFS method (breadth-first search), which is one of the graph traversal algorithms is employed to find all nodes and edges (i.e. project activities and dependencies) that are affected from $i{ }^{\text {th }}$ node. This search is performed for all nodes and founded set of edges and nodes are saved in a matrix, which is named edge dependency matrix (EDM). In the case of occurring rework from $j^{\text {th }}$ to $i^{\text {th }}$ activity, all activities that will be affected because of rework on activity $i$ are read from EDM matrix and then rework amounts are calculated and added to W (unfinished work) vector. The rework amount for affected activities that are not finished completely (at the time of happening rework risk) is computed only for the finished part of work. In other words, unfinished part of activity will be done without increasing in its amount when updated data from predecessor activities become ready after rework. The calculated amount of rework also depends on improvement curve and RIM off-diagonal coefficients.

The explained process repeats for the next event (system state) until for all activities $\mathrm{W}_{\mathrm{i}}=0$, which means there is not unfinished work or project is finished. At this time, simulation for current run ends and cumulative cost and duration are obtained. In addition, the number of occurred and not occurred risks are saved for further use in calculating the error (precision) of simulation.

\subsection{Modeling the uncertainty about parameters (variation)}

In the previous section we described the project simulation process for a determined value of duration and cost of activities in presence of risks. As noted in section 3.1 , in this paper we use triangular probability distributions for representing uncertainty about duration and cost of activities. At the beginning of each simulation run, random durations and costs are generated from corresponding probability distribution. Then, the simulation is performed without considering risks and the corresponding cost and duration of project are obtained. At the next stage, the simulation repeats with the same set of duration and cost of activities but this time with taking account the risk factor as described in previous section and again, the cost and duration of project are computed. 
At the end of each simulation run, the cumulative risk occurrence record is updated which is used for checking the criteria of terminating the simulation as follows:

$\operatorname{error}(i)=\frac{1}{K} \sum_{j=1}^{K}\left|P_{j}-\frac{n_{j, i}}{N_{j, i}}\right|$

Where: $i$ is number of accomplished simulation runs; $\mathrm{K}$ is total number of possible risks in project; $P_{j}$ is the probability of occurring $\mathrm{j}^{\text {th }}$ risk (as read from RPM); $\mathrm{n}_{\mathrm{j}, \mathrm{i}}$ is cumulative count of $j^{\text {th }}$ risk occurrences after $i$ simulations and $\mathrm{N}_{\mathrm{j}, \mathrm{i}}$ is cumulative checked cases for $\mathrm{j}^{\text {th }}$ risk occurrence after i simulation runs.

In fact, this criterion represents a measure of coincidence of occurred risks in simulation runs and expected probabilities in RPM matrix. The overall simulation algorithm that was described in sections 3.3 and 3.4 is represented below:

\section{START}

1. Import project data (DSM, RPM and RIM, parameters of probability distributions),

2. Create directed graph of project and EDM,

3. Generate random time and cost of each activity from its probability distribution,

4. Project simulation without risk effects

4.1. Find active work set $\left(\mathrm{W}_{\mathrm{n}}\right)$,

4.2. Calculate the duration of current event $\left(\min \left(\mathrm{t}_{\text {active }}\right)\right)$,

4.3. Calculate and update cost and work values for current event,

4.4. IF there is unfinished work $(\mathrm{W} \neq 0)$, create a new event and GOTO 4.1. IF NO, GOTO 4.5.,

4.5. Calculate total project time and cost (without risk),

5. Project simulation with risk effects

5.1. Initialize parameters for simulation with risk effects,

5.2. Find active work set $\left(\mathrm{W}_{\mathrm{n}}\right)$,

5.3. IF risk type 1,2 or 3 happens, GOTO 5.4. IF NO, GOTO 5.5.,

5.4. Calculate and add impact of risks to corresponding time, cost or work vector,
5.5 IF all activated activities checked, GOTO 5.6. , IF NO, for the next activity GOTO 5.3.,

5.6. Calculate the duration of current event $\left(\min \left(\mathrm{t}_{\text {active }}\right)\right)$,

5.7. Calculate and update cost and work values for current event,

5.8. IF there is any possible rework (risk type 4) for completed activities GOTO 5.9. , IF NO GOTO 5.12.,

5.9. IF rework happens, GOTO 5.10. IF NO, GOTO 5.11.,

5.10. Calculate first and second order rework values,

5.11. IF all reworks of current activity checked, GOTO 5.12. , IF NO, for next possible rework of activity

GOTO 5.9.,

5.12. IF all finished activities for current event checked, GOTO 5.13. , IF NO, for next finished activity GOTO 5.8.,

5.13. Update work vector (add all rework values to W),

5.14. IF there is unfinished work $(\mathrm{W} \neq 0)$, create a new event, GOTO 5.2. , IF NO, GOTO 5.15.,

5.15. Calculate the total project time and cost (with risk),

6. Calculate error for the current iteration,

7. IF error $>$ error $(\max )$, create a new simulation run (iteration), GOTO 3., IF NO, GOTO 8. ,

8. Plot and save results,

\section{END}

\section{Results}

The computer program for project simulation is written with MATLAB software and was implemented for a small turbojet engine preliminary design project, which can be installed on unmanned aerial vehicles or ultralight sport planes. The required simulation data were represented in section 3-2. The criteria for terminating the simulation was chosen 0.001 (error $=0.1 \%$ ). After 101290 simulations the desired error value was achieved, the simulation time on a PC with 4 GB RAM and CPU core i5 2.5 was 2656 seconds. In Tab. 6, the data of occurred risks (Eq. 2) for each risk is shown.

Table 6. Simulation results for occurred risks

\begin{tabular}{c|l|l|c|c|c|c}
\hline & Risk name & $\begin{array}{c}\text { Probability } \\
(\mathbf{e x p e c t e d )} \\
\left(\mathbf{P}_{\mathbf{j}}\right)\end{array}$ & $\begin{array}{c}\text { Occurred risks } \\
\left.\mathbf{( n}_{\mathbf{j}}\right)\end{array}$ & $\begin{array}{c}\text { All checked cases } \\
\left.\mathbf{( N}_{\mathbf{j}}\right)\end{array}$ & $\begin{array}{c}\text { Probability (simulation) } \\
\left(\mathbf{n}_{\mathbf{j}} / \mathbf{N}_{\mathbf{j}}\right)\end{array}$ & $\begin{array}{c}\text { Error } \\
(\mathbf{\%})\end{array}$ \\
\hline $\mathbf{1}$ & Rework from 7 to 2 & 0.6 & 146978 & 244661 & 0.6007 & 0.1236 \\
\hline $\mathbf{2}$ & Rework from 10 to 2 & 0.5 & 63787 & 127929 & 0.4986 & 0.2783 \\
\hline $\mathbf{3}$ & Rework from 10 to 1 & 0.3 & 46389 & 153605 & 0.4001 & 0.6629 \\
\hline $\mathbf{4}$ & Rework from 15 to 11 & 0.4 & 74623 & 186531 & 0.2018 & 0.0142 \\
\hline $\mathbf{5}$ & Rework from 16 to 11 & 0.2 & 23717 & 117507 & 0.2006 & 0.9091 \\
\hline $\mathbf{6}$ & Rework from 16 to 1 & 0.2 & 23589 & 117596 & 0.3003 & 0.2959 \\
\hline $\mathbf{7}$ & Cost risk on 7 & 0.3 & 109787 & 365642 & 0.4997 & 0.086 \\
\hline $\mathbf{8}$ & Delay risk on 10 & 0.5 & 109270 & 218664 & 0.2997 & 0.0567 \\
\hline $\mathbf{9}$ & Excess work on 12 & 0.3 & 65677 & 219111 & 0.6993 & 0.0857 \\
\hline $\mathbf{1 0}$ & Delay risk on 16 & 0.7 & 101044 & 144488 & & 0.0966 \\
\hline
\end{tabular}

For better understanding of simulation results, the result of a random simulation run is presented in Fig. 3. In this random run, 6 out of 16 possible risks (of all types) happened. 


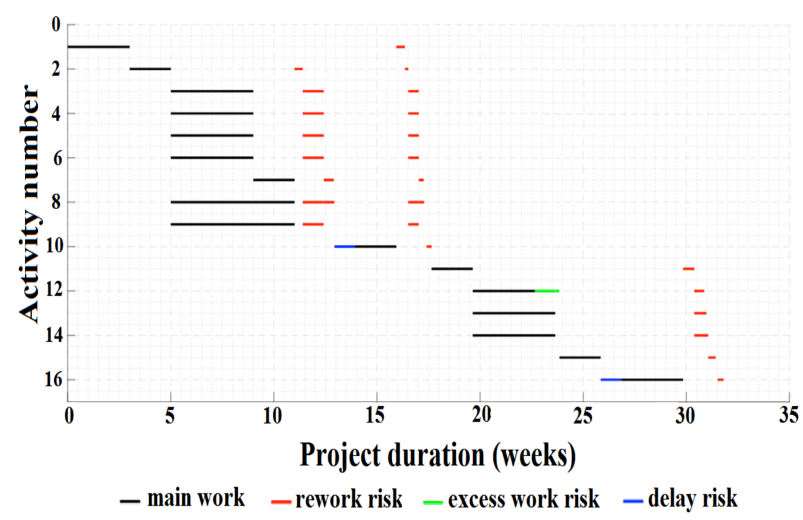

Fig. 3. Project Gantt chart for a random simulation run

In Fig. 4 and Fig. 5 the probability and cumulative distribution function (CDF) of project duration and cost after 101290 simulation runs are shown, with and without considering risks. In other words, yellow histograms (without risk) account for uncertainty in estimating the durations and costs of activities while blue histograms (with risk) add the effects of happening risks to them.
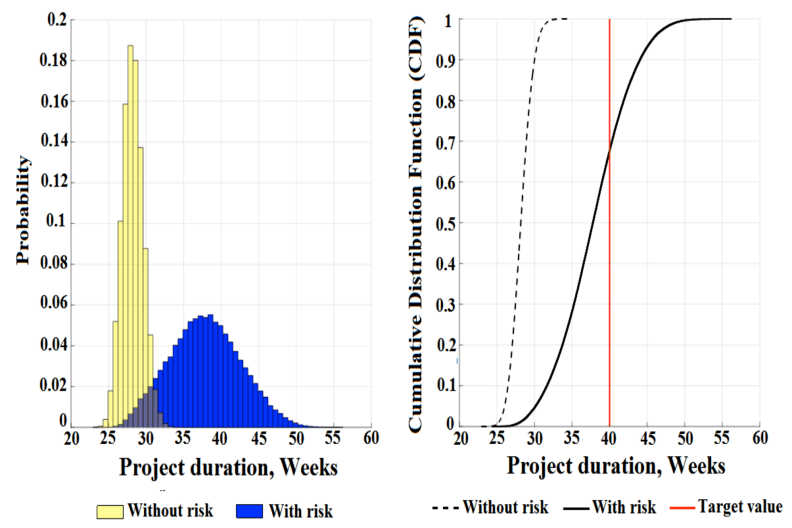
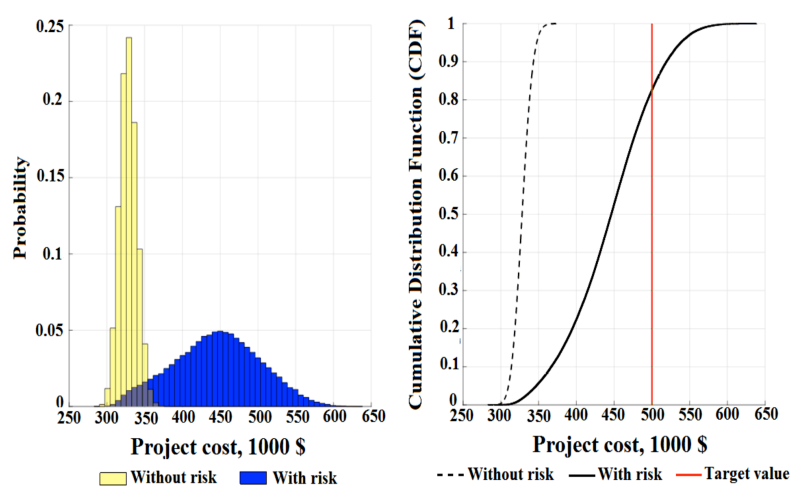

Fig. 5. Histogram and CDF for project cost

The results of simulation for project duration and cost mean values are shown in Tab. 7. In addition, the change of each parameter with respect to deterministic project without risk are calculated in this table. As it can be founded from Figures 4 and 5, these changes in duration and cost for higher probabilities (higher rate of confidence) increase.

Table 7. Mean values for project duration and cost

\begin{tabular}{l|c|c|c|c|c}
\hline & $\begin{array}{c}\text { Deterministic, } \\
\text { without risk }\end{array}$ & $\begin{array}{c}\text { Probabilistic } \\
\text { without risk }\end{array}$ & $\begin{array}{c}\% \\
\text { change }\end{array}$ & $\begin{array}{c}\text { Probabilistic, } \\
\text { with risk }\end{array}$ & $\begin{array}{c}\% \\
\text { change }\end{array}$ \\
\hline $\begin{array}{l}\text { Project } \\
\text { duration } \\
\text { (mean value) }\end{array}$ & 24 & 28.17 & +17.38 & 37.78 & +57.42 \\
$\begin{array}{l}\text { Project cost } \\
\text { (mean value) }\end{array}$ & 300 & 328.10 & +9.37 & 442.60 & +47.43 \\
\hline
\end{tabular}

In Fig. 6, three dimensional cost-duration diagram of project is presented which shows that the most probable variant of project realization is in the $[37,38.6]$ interval for duration (in weeks) and [430,447] interval for cost (in thousand dollars).

Fig. 4. Histogram and CDF for project duration

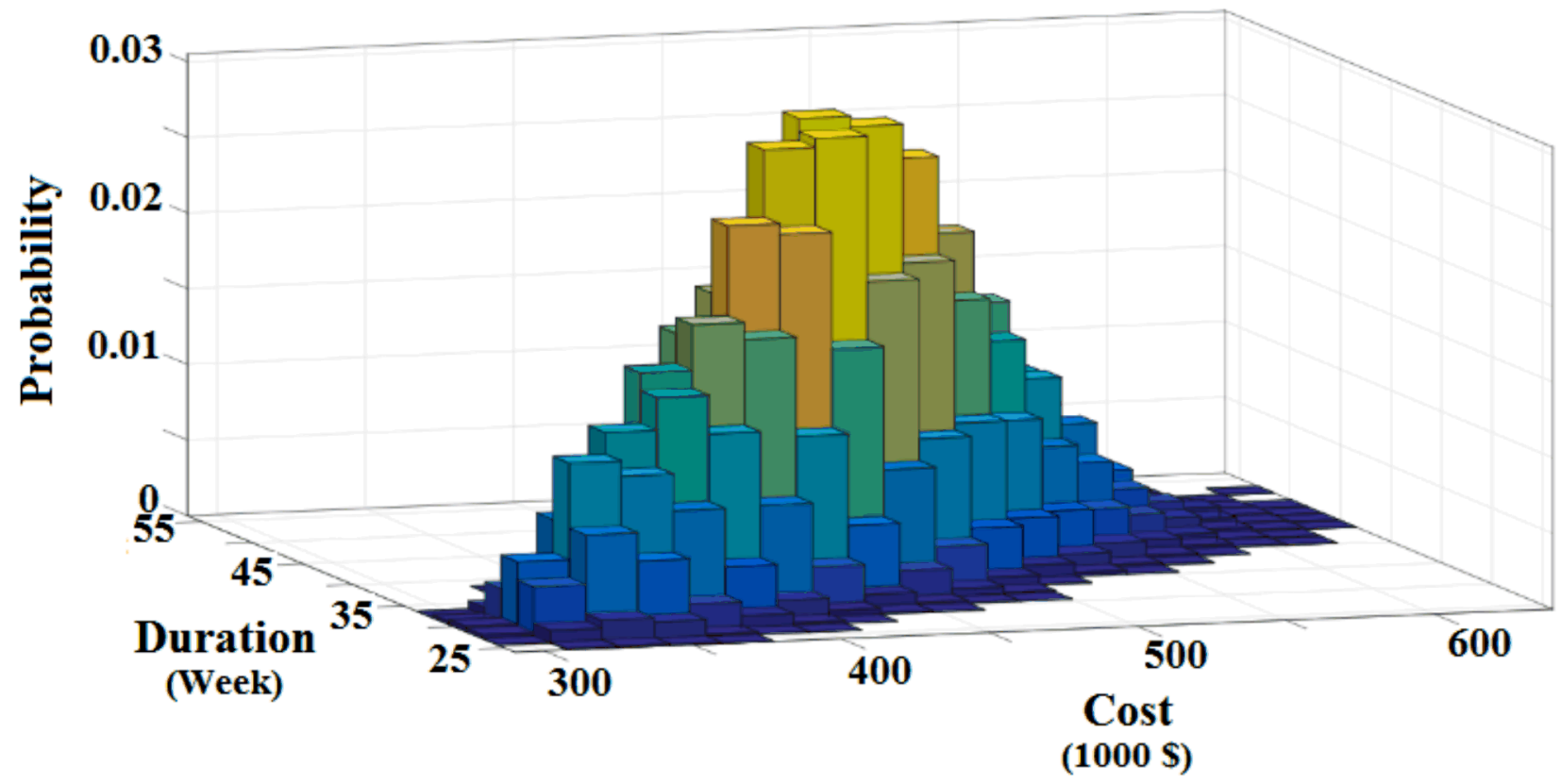

Fig. 6. Three dimensional cost-duration diagram 


\section{Analysis of results and conclusions}

Simulation result shows that if the maximum tolerable duration and cost (target values) for project are set to 40 weeks and 500 thousand dollars (as shown by red lines in figures 4 and 5), the probability of project failure because of delay and financial problems are $17.5 \%$ (Fig. 4) and $32.3 \%$ (Fig. 5). If project manager prefers to take prudent policy and wishes to be more confident about the project's termination cost and date in presence of uncertainty and risks, expected duration and cost increase considerably compared with $50 \%$ confidence (Tab. 7). For example, with $90 \%$ of confidence cost overrun will increase from $47.43 \%$ to $73.7 \%$ and for project duration, it would increase from $57.4 \%$ to $83.5 \%$.

Similarly, using the results of performed simulation helps manager to conduct different analyses and make proper decisions. For example, the contribution of variation in estimating duration and cost of activities and risk factors in main project parameters can be evaluated which in turn results in more effective management of required preventive or corrective reactions.
Overall, the results of this study can help project managers as an efficient tool to evaluate the duration and cost of project in the presence of uncertainty in estimates and different risk factors (especially rework risks, which are a prominent aspect in research and development projects). Consequently, these results improve the decision-making process where appropriate method for managing and reducing risk effects under uncertainty conditions should be selected.

Some limitations of this study and suggestions for further work are as follows: i. Considering resource constraints in project, ii. Improving the sampling method in order to speed up simulation, iii. Finding the best risk management strategy, which optimizes project cost and time. This problem can be represented as a multicriteria optimization and iv. Improving the simulation algorithm for multi-level WBS.

This is an Open Access article distributed under the terms of the Creative Commons Attribution Licence

\section{References}

1. S. Ward, and C. Chapman, Transforming project risk management into project uncertainty management., International journal of project management, 21(2), p. 97-105 (2003).

2. A. Jaafari, Management of risks, uncertainties and opportunities on projects: time for a fundamental shift., International journal of project management, 19(2), p. 89-101 (2001).

3. R. Atkinson, L. Crawford, and S. Ward, Fundamental uncertainties in projects and the scope of project management., International journal of project management, 24(8), p. 687-698 (2006).

4. D. Hillson, Managing risk in projects., Gower Publishing, Ltd. (2009).

5. O. Perminova, M. Gustafsson, and K. Wikström, Defining uncertainty in projects-a new perspective., International Journal of Project Management, 26(1), p. 73-79 (2008).

6. F.H. Knight, Risk, uncertainty and profit., Courier Corporation (2012).

7. L. Lehtiranta, Risk perceptions and approaches in multiorganizations: A research review 2000-2012., International Journal of Project Management, 32(4), p. 640-653 (2014).

8. A.M.T. Thomé, L.F. Scavarda, A. Scavarda, and F.E.S.S. Thomé, Similarities and contrasts of complexity, uncertainty, risks, and resilience in supply chains and temporary multi-organization projects., International Journal of Project Management, 34(7), p. 1328-1346 (2016)

9. A guide to the project management body of knowledge : (PMBOK ${ }^{\circledR}$ guide), Project management Institute, Newtown Square, Pa., (2013).

10. H. Thamhain, Managing risks in complex projects., Project Management Journal, 44(2), p. 20-35 (2013).

11. V. Lévárdy, and T.R. Browning, An adaptive process model to support product development project management., IEEE Transactions on Engineering Management, 56(4), p. 600-620 (2009).

12. T.R. Browning, and S.D. Eppinger, Modeling impacts of process architecture on cost and schedule risk in product development., IEEE transactions on engineering management, 49(4), p. 428-442 (2002).

13. S.H. Cho, and S.D. Eppinger, A simulation-based process model for managing complex design projects., IEEE Transactions on engineering management, 52(3), p. 316-328 (2005).

14. Q. Yang, T. Lu, T. Yao, and B. Zhang, The impact of uncertainty and ambiguity related to iteration and overlapping on schedule of product development projects., International Journal of Project Management, 32(5), p. 827-837 (2014).
15. J.F. Maier, D.C. Wynn, W. Biedermann, U. Lindemann, and P.J. Clarkson, Simulating progressive iteration, rework and change propagation to prioritise design tasks., Research in Engineering Design, 25(4): p. 283-307 (2014)

16. S.A. Koba, and E.A. Druzhinin, Simulation modeling of technical and economical indicators of complex projects (in russian)., Control systems, navigation and communication, 3(27), p. 129135 (2013).

17. C. Chapman, S. Ward, and I. Harwood, Minimising the effects of dysfunctional corporate culture in estimation and evaluation processes: A constructively simple approach., International journal of project management, 24(2), p. 106-115 (2006).

18. I.I. Mazur, V.D. Shapiro, N.G. Olderogge, and A.V. Polkovnikov, Project management, 5th ed. (in russian), Omega-L, Moscow (2009).

19. A. De Meyer, C.H. Loch, and M.T. Pich, Managing project uncertainty: from variation to chaos., MIT Sloan Management Review, 43(2), p. 60 (2002).

20. E.A. Druzhinin, Methodological basis of the risk-oriented approach to resource management in technical system development projects and programs (Doctor of technical sciences thesis in russian), National Aerospace University named after N. E. Zhukovsky (2006).

21. M.S. Islam, and M. Nepal, A Fuzzy-bayesian Model for Risk Assessment in Power Plant Projects., Procedia Computer Science, 100, p. 963-970 (2016).

22. B. Yet, A. Constantinou, N. Fenton, M. Neil, E. Luedeling, and K. Shepherd, A Bayesian network framework for project cost, benefit and risk analysis with an agricultural development case study., Expert Systems with Applications, 60, p. 141-155 (2016).

23. C. Kumar, and D.K. Yadav, A probabilistic software risk assessment and estimation model for software projects., Procedia Computer Science, 54, p. 353-361 (2015).

24. V. Khodakarami, and A. Abdi, Project cost risk analysis: A Bayesian networks approach for modeling dependencies between cost items., International Journal of Project Management, 32(7), p. 1233-1245 (2014).

25. T.H. Nguyen, F. Marmier, and D. Gourc, A decision-making tool to maximize chances of meeting project commitments., International Journal of Production Economics, 142(2), p. 214224 (2013).

26. K. Rudnik, and A.M. Deptuła, System with probabilistic fuzzy knowledge base and parametric inference operators in risk assessment of innovative projects., Expert Systems with Applications, 42(17), p. 6365-6379 (2015). 
27. A. Rodríguez, F. Ortega, and R. Concepción, A method for the evaluation of risk in IT projects. Expert Systems with Applications, 45, p. 273-285 (2016).

28. C. Muriana, and G. Vizzini, Project risk management: A deterministic quantitative technique for assessment and mitigation., International Journal of Project Management, 35(3), p. 320-340 (2017).

29. F. Acebes, J. Pajares, J.M. Galán, and A. López-Paredes, Exploring the influence of seasonal uncertainty in project risk management., Procedia-Social and Behavioral Sciences, 119, p. 329-338 (2014).
30. W. Li, and Y.B. Moon, A simulation study of mutual influences of engineering change management process and new product development process., Proceedings of the Simulation Conference, Austin, USA, p. 2940-2950 (2009)

31. D.V. Steward, The design structure system: A method for managing the design of complex systems., IEEE transactions on Engineering Management, 1981(3), p. 71-74 (1981).

32. R. Ahmadi, T.A. Roemer, and R.H. Wang, Structuring product development processes., European Journal of Operational Research, 130(3), p. 539-558 (2001).

33. J.C. Goodpasture, Quantitative methods in project management., J. Ross Publishing, 268p. (2003). 